\title{
NODULAÇÃO E PRODUÇ̃̃O DE RAÍZES DO ESTILOSANTES MINEIRÃO SOB EFEITO DE CALA̧GEM, SILICATAGEM E DOSES DE FÓSFORO
}

\author{
Nodulation and root production of stylosanthes Mineirão under the \\ effect of lime, silicate and phosphorus
}

\author{
Jalison Lopes ${ }^{1}$, Antônio Ricardo Evangelista², Caio Augustus Fortes², José Cardoso Pinto², \\ Antônio Eduardo Furtini Neto ${ }^{3}$, Ronan Magalhães de Souza ${ }^{4}$
}

\begin{abstract}
RESUMO
Objetivou-se, com este trabalho, avaliar o efeito do uso de dois corretivos de acidez do solo e de doses crescentes de fósforo, sobre a nodulação, produção de matéria seca, acúmulos e teores dos nutrientes nas raízes do estilosantes Mineirão (Stylosanthes guianensis (Aubl.) Sw. cv. Mineirão). O experimento foi conduzido em casa-de-vegetação com delineamento experimental em blocos casualizados, com três repetições. Os tratamentos foram dispostos em esquema fatorial 5x2, constituído por cinco doses de $\mathrm{P}$ (50, $100,200,400$ e $800 \mathrm{mg} \mathrm{dm}^{-3}$ de solo) e dois tipos de corretivo (calcário dolomítico e silicato de $\mathrm{Ca}$ e $\mathrm{Mg}$ ). A produção de matéria seca de raízes, a nodulação e o acúmulo dos nutrientes $\mathrm{P}, \mathrm{N}, \mathrm{Ca}$ e $\mathrm{Zn}$ foram maiores quando a adubação esteve associada ao silicato. Entretanto, a aplicação de doses superiores a $257 \mathrm{mg} \mathrm{dm}^{-3} \mathrm{de} \mathrm{P}$ na presença de silicato, inibiu o desenvolvimento do sistema radicular do Mineirão, provavelmente por causa de uma interação negativa entre os nutrientes $\mathrm{P}$ e Zn, causada pela alta disponibilidade de P.
\end{abstract}

Termos para indexação: Silicato de Ca e Mg, calcário, raízes, Stylosanthes guianensis.

\begin{abstract}
The objective of this research was to evaluate the effect of two soil correctives and P rates on nodulation, dry matter production, accumulation and content of nutrients in the roots of Stylosanthes guianensis (Aubl.) Sw. cv. Mineirão. The experiment was performed in a greenhouse. A randomized blocks design was used in a $5 \times 2$ factorial arrangement, with five $\mathrm{P}$ rates $(50,100,200$, 400 and $800 \mathrm{mg} \mathrm{dm}^{-3}$ soil) and two soil correctives (lime and silicate) with three replicates. The dry matter production of roots, nodulation and nutrient accumulation of $\mathrm{P}, \mathrm{N}, \mathrm{Ca}$ and $\mathrm{Zn}$ increased with the association between fertilizer and silicate. However, the application of $\mathrm{P}$ higher than $257 \mathrm{mg} \mathrm{dm}^{-3}$ in the presence of silicate, inhibit the development of the root system of Mineirão, probably due to a negative interaction between $\mathrm{Zn}$ and $\mathrm{P}$ nutrients, caused by the high availability of $\mathrm{P}$.
\end{abstract}

Index terms: $\mathrm{Ca}$ and $\mathrm{Mg}$ silicate, lime, roots, Stylosanthes guianensis.

(Recebido em 30 de abril de 2009 e aprovado em 6 de julho de 2010)

\section{INTRODUÇÃO}

A baixa disponibilidade natural de fósforo $(\mathrm{P}) \mathrm{e}$ nitrogênio $(\mathrm{N})$ verificada nos solos tropicais, associada à forma de exploração extrativista que é praticada na maioria das regiões produtoras são os principais fatores responsáveis pela degradação das pastagens brasileiras. Diante dessa realidade é grande a demanda por tecnologias que possibilitem o restabelecimento da capacidade produtiva das pastagens de forma econômica e sustentável.

As leguminosas, que são capazes de realizar a fixação biológica de $\mathrm{N}$, por meio da simbiose com as bactérias do gênero Rhizobium, representam uma importante fonte desse nutriente para o sistema e de forragem de alta qualidade para produção animal. Dentre os gêneros de leguminosas forrageiras destaca-se o
Stylosanthes, por sua ampla adaptação e resistência às pressões bióticas e abióticas.

O P é um nutriente essencial para o desenvolvimento radicular e perfilhamento, passando a sua deficiência a limitar a capacidade produtiva das pastagens (Guss et al., 1990). Além disso, o P é um elemento muito importante para a nutrição das leguminosas (Andrew \& Jones, 1978) e para a nodulação e fixação de $\mathrm{N}_{2}$ (Chaudhary \& Fujita, 1998).

Em solos ácidos, o crescimento das leguminosas e a fixação simbiótica de $\mathrm{N}_{2}$ são afetados por vários fatores, entre os quais estão o baixo $\mathrm{pH}$ e a baixa concentração de cálcio (Ca) na solução do solo, limitando tanto a nodulação, como o crescimento da planta hospedeira (Andrew, 1976). Outro fator prejudicial é a toxicidade do alumínio, reduzindo o crescimento das plantas e a nodulação (Murphy et al., 1984). Portanto, o emprego de calcário dolomítico, além

\footnotetext{
1Universidade Federal de Roraima/UFRR - Centro de Ciências Agrárias - Rodovia BR 174 - km 12 - 69300-000 - Boa Vista, RR - jalisonufla@gmail.com 2Universidade Federal de Lavras/UFLA - Departamento de Zootecnia/DZO - Lavras, MG

${ }^{3}$ Universidade Federal de Lavras/UFLA - Departamento de Ciência do Solo/DCS - Lavras, MG

${ }^{4}$ Centro Universitário de Patos de Minas - Patos de Minas, MG
} 
de corrigir a acidez e neutralizar o alumínio tóxico, introduz nutrientes como $\mathrm{Ca}$ e magnésio $(\mathrm{Mg})$ e atua tornando disponível para as plantas nutrientes essenciais como $\mathrm{P}$ e molibdênio (Mo), os quais, em solos ácidos, estão imobilizados em formas não disponíveis para as plantas.

Nós últimos anos, houve crescimento das pesquisas em que silicatos são utilizados para substituir o tradicional calcário, visto que, além de corrigir a acidez do solo e elevar o pH, com reações semelhantes ao calcário, o ânion silicato $\left(\mathrm{H}_{3} \mathrm{SiO}_{4}^{-}\right)$disponibilizado, concorre com o ânion fosfato pelo mesmo sítio de adsorção, saturando, dessa forma, o ponto onde possivelmente seria adsorvido o $\mathrm{P}$ e, consequentemente, aumentando a disponibilidade desse nutriente para as culturas (Souza et al., 2009).

As raízes são o elo entre a parte aérea da planta e o solo e o seu estudo é um parâmetro eficaz para avaliação dos efeitos do uso do solo, principalmente no que diz respeito à sua relação com sistema solo-planta.

Portanto, objetivou-se, com esta pesquisa, avaliar os efeitos do uso de dois corretivos de acidez do solo, e de doses crescentes de fósforo sobre a nodulação, produção de matéria seca, acúmulos e teores de nutrientes das raízes do estilosantes Mineirão (Stylosanthes guianensis (Aubl.) Sw. cv. Mineirão).

\section{MATERIAL E MÉTODOS}

O experimento foi conduzido em casa de vegetação, do Departamento de Ciência do Solo da Universidade Federal de Lavras, Minas Gerais (UFLA), no período de agosto de 2006 a março de 2007. Foi utilizado um solo classificado como Latossolo Vermelho Distroférrico (Empresa Brasileira de Pesquisa Agropecuária - Embrapa, 2006), textura muito argilosa (70\% de argila), procedente do Departamento de Zootecnia da UFLA. O solo foi coletado a uma profundidade de $0-20 \mathrm{~cm}$ sendo, posteriormente, passado em peneira com malha de cinco mm de abertura, para remoção de cascalhos e fragmentos de raízes, e, em seguida seco ao ar.

Após os procedimentos iniciais, amostras desse solo foram analisadas química e fisicamente (Tabela 1). Metade do solo foi submetido à calagem e a outra metade a silicatagem, levando-se em consideração o método de saturação por bases para se elevar o valor $\mathrm{V}$ de $44 \%$ para $60 \%$, utilizando-se calcário dolomítico $(99,02 \%$ de PRNT) e silicato de $\mathrm{Ca}$ e $\mathrm{Mg}$ (53\% de PRNT), proveniente da indústria de ferro gusa. Decorrida a aplicação dos corretivos, o solo permaneceu incubado por 165 dias, com a umidade do solo mantida na capacidade de campo, por meio de pesagem diária e adição de água destilada, quando necessário. Esse período de incubação foi utilizado para garantir que a reação do silicato com o solo fosse completa, em virtude do baixo PRNT apresentado por esse corretivo. $\mathrm{O}$ delineamento experimental utilizado foi em blocos casualizados, com três repetições, com os tratamentos dispostos num esquema fatorial $5 \times 2$, constituídos por cinco doses de $\mathrm{P}\left(50,100,200,400\right.$ e $800 \mathrm{mg} \mathrm{dm}^{-3}$ de solo) e dois corretivos totalizando 10 tratamentos.

Tabela 1 - Caracterização química e física do solo utilizado.

\begin{tabular}{lc}
\hline Atributos & Valores \\
\hline $\mathrm{pH}$ em água & 5,6 \\
$\mathrm{P}\left(\mathrm{mg} \mathrm{dm}^{-3}\right)$ & 1,4 \\
$\mathrm{~K}^{+}\left(\mathrm{mg} \mathrm{dm}^{-3}\right)$ & 55 \\
$\mathrm{Ca}^{2+}\left(\mathrm{cmol}_{\mathrm{c}} \mathrm{dm}^{-3}\right)$ & 2,1 \\
$\mathrm{Mg}^{2+}\left(\mathrm{cmol}_{\mathrm{c}} \mathrm{dm}^{-3}\right)$ & 0,9 \\
$\mathrm{Al}^{3+}\left(\mathrm{cmol}_{\mathrm{c}} \mathrm{dm}^{-3}\right)$ & 0,2 \\
$\mathrm{H}^{+}+\mathrm{Al}^{3+}\left(\mathrm{cmol}_{\mathrm{c}} \mathrm{dm}^{-3}\right)$ & 4 \\
$\mathrm{~S}\left(\mathrm{mg} \mathrm{dm}^{-3}\right)$ & 41,4 \\
$\mathrm{SB}\left(\mathrm{cmol}_{\mathrm{c}} \mathrm{dm}^{-3}\right)$ & 3,1 \\
$\mathrm{t}\left(\mathrm{cmol}_{\mathrm{c}} \mathrm{dm}^{-3}\right)$ & 3,3 \\
$\mathrm{~T}\left(\mathrm{cmol}_{\mathrm{c}} \mathrm{dm}^{-3}\right)$ & 7,1 \\
$\mathrm{~m}(\%)$ & 6 \\
$\mathrm{~V}(\%)$ & 44 \\
Matéria orgânica $(\%)$ & 3,7 \\
P-rem $\left(\mathrm{mg} \mathrm{L}^{-1}\right)$ & 18,8 \\
Areia $(\%)$ & 14 \\
Silte $(\%)$ & 16 \\
Argila $(\%)$ & 70 \\
\hline Árises &
\end{tabular}

Análises efetuadas no Laboratório de Fertilidade do Solo do DCS - UFLA.

O solo foi acondicionado em vasos plásticos sem furos com capacidade para $4,0 \mathrm{dm}^{3}$ que receberam as cinco doses de $\mathrm{P}$ na forma de $\mathrm{H}_{3} \mathrm{PO}_{4}$ e uma adubação básica de plantio que constou de $120 \mathrm{mg} \mathrm{dm}^{-3} \mathrm{de} \mathrm{K}$, aplicado na forma de $\mathrm{K}_{2} \mathrm{SO}_{4}$ mais os micronutrientes: $\mathrm{Zn}\left(1,59 \mathrm{mg} \mathrm{dm}^{-3}\right), \mathrm{B}$ $\left(1,57 \mathrm{mg} \mathrm{dm}^{-3}\right), \mathrm{Cu}\left(0,33 \mathrm{mg} \mathrm{dm}^{-3}\right), \mathrm{Mn}\left(0,84 \mathrm{mg} \mathrm{dm}^{-3}\right)$, Mo $\left(0,15 \mathrm{mg} \mathrm{dm}^{-3}\right)$ e Co $\left(0,01 \mathrm{mg} \mathrm{dm}^{-3}\right)$, aplicados, respectivamente, nas formas de $\mathrm{ZnSO}_{4}, \mathrm{H}_{3} \mathrm{BO}_{3}, \mathrm{CuSO}_{4}$ $\mathrm{MnSO}_{4},\left(\mathrm{NH}_{4}\right)_{6} \mathrm{Mo}_{7} \mathrm{O}_{24}$ e $\mathrm{CoCl}_{2}$.

A semeadura foi efetuada utilizando 20 sementes da leguminosa por vaso. O desbaste foi realizado 15 dias após a emergência, deixando-se cinco plantas por vaso.

A umidade do solo foi ajustada para atingir $60 \%$ do volume total de poros, e assim mantida por meio de 
pesagens periódicas, durante todo o período experimental que teve duração de 68 dias. Ao final do período experimental, foi realizado corte das plantas, a $5 \mathrm{~cm}$ do solo. Posteriormente, foi retirado o solo de cada vaso e as raízes foram separadas por lavagem em água corrente sobre peneira de $0,5 \mathrm{~mm}$ de malha, sendo realizada em seguida a contagem do número total de nódulos. As raízes foram secas em estufa com circulação de ar a $55^{\circ} \mathrm{C}$ por $72 \mathrm{~h}$, na sequência foram pesadas para determinação da produção de matéria seca e, posteriormente, foram moídas em moinho tipo Willey.

Os teores de $\mathrm{N}$ foram determinados pelo método semi micro Kjeldahl, descrito por Silva (1998). Os teores de $\mathrm{P}, \mathrm{Ca}, \mathrm{Mg}$ e $\mathrm{Zn}$ foram determinados conforme metodologia descrita por Sarruge \& Haag (1974). O acúmulo de N, P, Ca e Mg, nas raízes foi obtido por meio da multiplicação de seus teores na matéria seca pela quantidade de matéria seca produzida. Para efeito de análises estatísticas, os dados referentes ao número de nódulos foram transformados em $\sqrt{+1}$. A análise de variância foi realizada por meio do programa computacional Sistema de Análise de Variância para Dados Balanceados (SISVAR) (Ferreira, 2008).

\section{RESULTADOS E DISCUSSÃO}

Na Figura 1, observa-se o efeito da interação doses de $\mathrm{P}$ x corretivos sobre a produção de matéria seca das raízes do estilosantes Mineirão $(\mathrm{P}<0,05)$.

No solo corrigido com silicato, a dose de $\mathrm{P}$ que proporcionou a máxima produção de matéria seca (MS) de raízes $\left(8,77 \mathrm{~g} \mathrm{vaso}^{-1}\right)$ foi $257 \mathrm{mg} \mathrm{dm}^{-3}$. No solo corrigido com calcário, a resposta da produção de MS de raízes aos incrementos nas doses de $\mathrm{P}$ foi linear e positiva.

É provável que a maior disponibilização de $\mathrm{P}$ na presença de silicato ocasionou inibição da absorção de Zn pelo Mineirão, a partir da aplicação de $257 \mathrm{mg} \mathrm{dm}^{-3}$ de $\mathrm{P}$, prejudicando o desenvolvimento do sistema radicular da leguminosa, já que, o excesso de $\mathrm{P}$ disponível no solo pode inibir de forma competitiva a absorção de $\mathrm{Zn}$ (Malavolta et al., 1997).

Ao comparar as produções máximas de MS de raízes para ambos corretivos testados, com a aplicação, de uma quantidade de fósforo $68 \%$ inferior ( $257 \mathrm{vs} 800 \mathrm{mg} \mathrm{dm}^{-3}$ ) observa-se superioridade de aproximadamente $17 \%$ a favor da interação $\mathrm{P}$ x silicato $\left(8,77\right.$ vs 7,29 $\left.\mathrm{g} \mathrm{vaso}^{-1}\right)$. Comprovando a capacidade do silicato de disponibilizar mais $\mathrm{P}$ do solo e refletindo positivamente na produção de MS de raízes do estilosantes.

Souza et al. (2000), também demonstraram resultados significativos da adubação fosfatada sobre a produção de massa seca do sistema radicular de Stylosanthes guianensis. Por outro lado, Carneiro et al. (1999) não observaram efeito de doses de $\mathrm{P}$ sobre esse mesmo parâmetro.

O Si proveniente do silicato também pode ter favorecido o desenvolvimento do sistema radicular do Mineirão. Em leguminosas, tais como o feijão e a soja, o suprimento de silício ao meio de cultivo foi responsável por aumentos no comprimento e massa das raízes (Horst \& Marschner, 1978; Miyake \& Takahashi, 1985).

Na Figura 2, observa-se o efeito da interação doses de $\mathrm{P}$ x corretivos sobre o número de nódulos do estilosantes Mineirão $(\mathrm{P}<0,01)$.

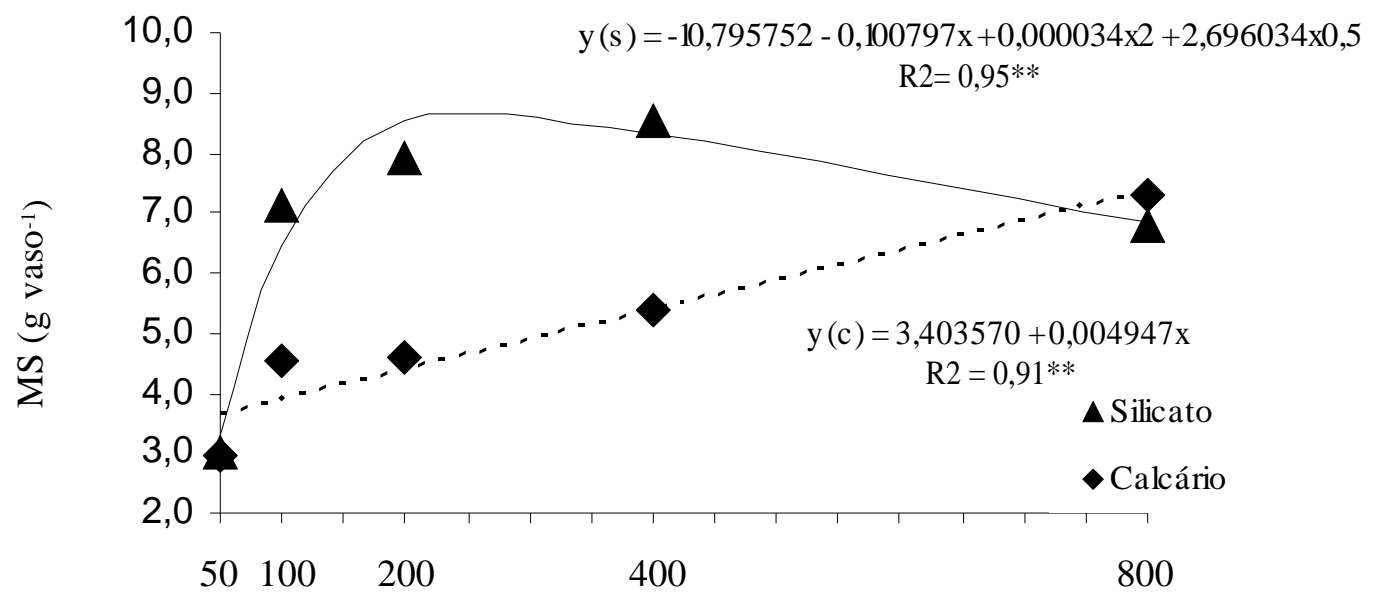

Doses de $\mathrm{P}\left(\mathrm{mg} \mathrm{dm}^{-3}\right)$

Figura 1 - Produção de matéria seca das raízes do estilosantes Mineirão. 


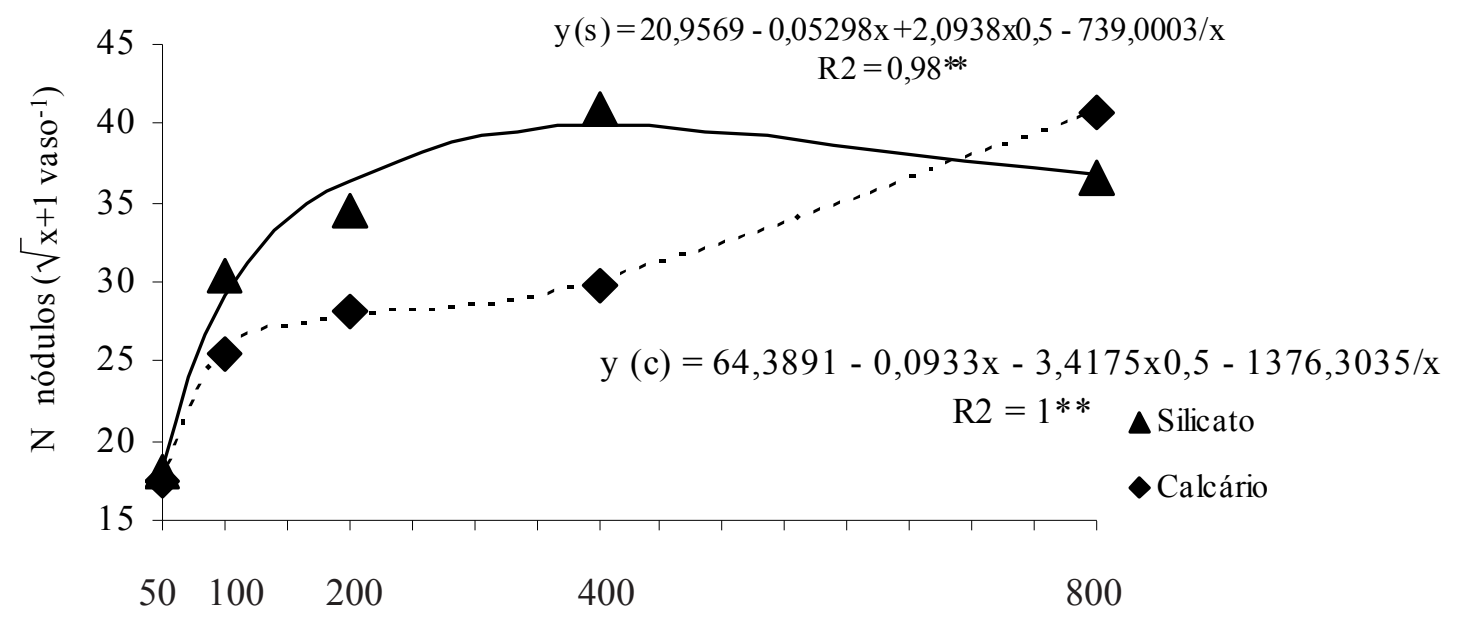

Doses de $\mathrm{P}\left(\mathrm{mg} \mathrm{dm}^{-3}\right)$

Figura 2 - Número de nódulos do estilosantes Mineirão.

No solo corrigido com silicato, a dose de $\mathrm{P}$ que proporcionou a máxima nodulação (40 nódulos vaso $^{-1}$ ) foi $353 \mathrm{mg} \mathrm{dm}^{-3}$. No solo corrigido com calcário, a máxima nodulação (41 nódulos vaso-1) foi verificada apenas na maior dose de $\mathrm{P}$ aplicada.

Possivelmente, a redução do número de nódulos observada na interação $\mathrm{P}$ x silicato, a partir de $353 \mathrm{mg} \mathrm{dm}^{-3}$ de $\mathrm{P}$, está associada à menor produção de raízes (Figura 1). Pode-se inferir que, mesmo o suprimento de $\mathrm{P}$ sendo suficiente para promover uma adequada atividade nodular, o menor volume de raízes produzido reduziu os sítios que poderiam ser infectados pelas bactérias do gênero Rhizobium. Asituação em que se verificou o maior equilíbrio bioeconômico entre disponibilidade de nutrientes, crescimento radicular e nodulação foi observada com aplicação de $257 \mathrm{mg} \mathrm{dm}^{-3}$ de P na presença de silicato, pois se observou a máxima produção de MS de raízes com número de nódulos inferior ao máximo (38 nódulos). Isso indica o uso mais eficiente do $\mathrm{N}$ fixado biologicamente, para o crescimento do sistema radicular.

O P tem participação ativa no processo de formação dos nódulos (Kolling et al., 1974) e respostas positivas da contagem de nódulos em leguminosas forrageiras a incrementos na adubação fosfatada também foram observadas em Cajanus cajan(L.) Millsp.(Costa et al., 1989) e leguminosas de clima temperado (Krolow et al., 2004). Em outro estudo, a contagem e peso de nódulos em feijão caupi foi influenciada positivamente por doses crescentes de Si (Nelwamondo \& Dakora, 1999). Isso indica que, provavelmente, o $\mathrm{Si}$ adicionado ao solo com o uso do silicato também beneficiou a nodulação do Mineirão.
Na Figura 3, observa-se o efeito da interação P x corretivos sobre o teor de $\mathrm{P}(\mathrm{P}<0,01)$ e sobre o $\mathrm{P}$ acumulado $(\mathrm{P}<0,05)$ nas raízes do estilosantes Mineirão.

Para a interação P x silicato, o teor mínimo de $\mathrm{P}$ nas raízes foi observado com a aplicação de $145 \mathrm{mg} \mathrm{dm}^{-3} \mathrm{de} P$. (Figura 3a). Isso resulta do efeito de diluição, em consequência dos elevados incrementos de MS de raízes observados (Figura 1). O elevado teor de P observado nas raízes da leguminosa com a aplicação de $800 \mathrm{mg} \mathrm{dm}^{-3} \mathrm{de} P$ reside no fato da absorção de $\mathrm{P}$ ter sido crescente, porém não ter sido acompanhada de ganhos proporcionais em massa seca, resultando na maior concentração desse nutriente. Para a dose $50 \mathrm{mg} \mathrm{dm}^{-3}$ de $\mathrm{P}$ aplicado, considerando que as produções de matéria seca foram semelhantes entre os corretivos, o maior teor de $\mathrm{P}$ observado na presença de silicato, demonstra, claramente, o efeito positivo deste corretivo na absorção de P.

Verificou-se resposta linear crescente do $\mathrm{P}$, acumulado nas raízes, aos incrementos nas doses de $\mathrm{P}$ aplicadas para os dois corretivos avaliados, com os maiores valores observados para a interação $\mathrm{P}$ x silicato. A silicatagem proporcionou acúmulo de $0,024 \mathrm{mg}_{\text {vaso }}{ }^{-1}$ de $\mathrm{P}$ na raíz para cada $\mathrm{mg} \mathrm{dm}^{-3}$ de $\mathrm{P}$ aplicado ao solo. Já, a calagem proporcionou acúmulo de $0,018 \mathrm{mg}$ vaso $^{-1}$, ou seja, uma superioridade $25 \%$ a favor do uso do silicato.

Fica claro que, em situações de maior disponibilidade de P no solo, como provavelmente ocorreu com a presença do silicato, o Mineirão é capaz de acumular maiores quantidades deste elemento em seu sistema radicular. Assim, como neste trabalho, Guss et al. (1990), também observaram boa capacidade de absorção de $\mathrm{P}$ em 
Stylosanthes guianensis em resposta a doses crescentes desse nutriente. Os principais fatores que afetam a absorção de $\mathrm{P}$ pela plantas são a taxa de crescimento radicular, a concentração do $\mathrm{P}$ na solução do solo e raio médio das raízes (Rosolem et al., 1994). Dessa forma, conclui-se que o maior acúmulo de $\mathrm{P}$ na presença do silicato resulta de maior disponibilização desse nutriente no solo, o que possibilitou maior desenvolvimento do sistema radicular (Figura 1), aumentando a capacidade exploratória das raízes e a capacidade de aquisição de nutrientes.

Na Figura 4, observa-se o efeito da interação P x corretivos sobre o teor de $\mathrm{N}(\mathrm{P}<0,01)$ e sobre o $\mathrm{N}$ acumulado $(\mathrm{P}<0,05)$ nas raízes do estilosantes Mineirão.

Para a interação $\mathrm{P} x$ silicato, foi verificado menor teor de $\mathrm{N}$ com a aplicação de $110 \mathrm{mg} \mathrm{dm}^{-3}$ de P. Isso ocorreu porque a quantidade biologicamente fixada de $\mathrm{N}$ foi proporcionalmente inferior ao desenvolvimento da planta.
A fixação biológica de nitrogênio (FBN) além de ter que ser capaz de atender à demanda de $\mathrm{N}$ das raízes, também precisa atender à demanda de $\mathrm{N}$ da parte aérea. Com os incrementos no desenvolvimento radicular e na nodulação (Figuras 1 e 2), o aporte de $\mathrm{N}$ biologicamente fixado também foi proporcionalmente mais acentuado, resultando em elevação no teor de $\mathrm{N}$, a partir da aplicação de $110 \mathrm{mg} \mathrm{dm}^{-3} \mathrm{de} \mathrm{P}$.

Para a interação $\mathrm{P}$ x calcário, o teor de $\mathrm{N}$ não apresentou comportamento claramente determinado, inclusive, não se ajustando ao estudo de regressão. Da mesma forma que ocorreu para a interação P x silicato, as oscilações nos teores de $\mathrm{N}$ em função das doses de $\mathrm{P}$ aplicadas foram decorrentes do grau de sincronização existente entre nodulação, FBN e o desenvolvimento da planta.

$\mathrm{O}$ máximo acúmulo de $\mathrm{N}$ nas raízes do estilosantes Mineirão plantado no solo corrigido com silicato (113 mg vaso-1)

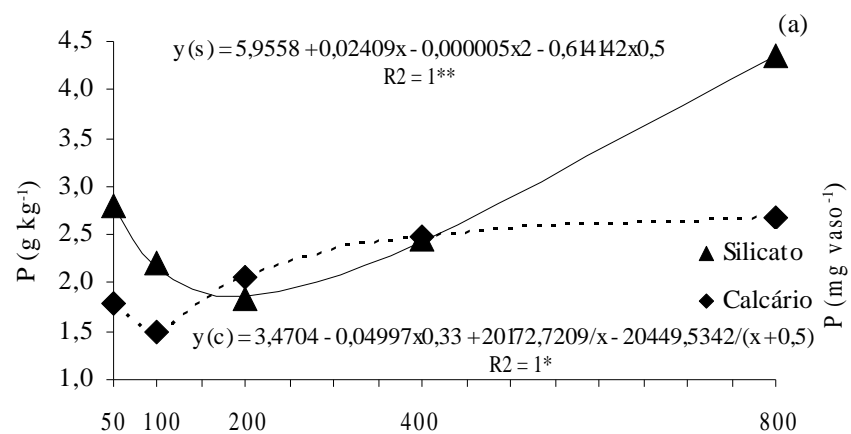

Doses de $\mathrm{P}\left(\mathrm{mg} \mathrm{dm}^{-3}\right)$

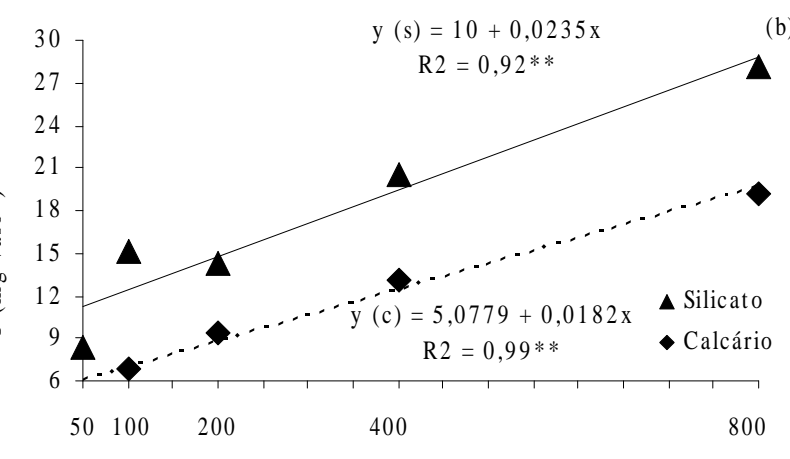

Doses de $\mathrm{P}\left(\mathrm{mg} \mathrm{dm}^{-3}\right)$

Figura 3 - Teor (a) e acúmulo (b) de P nas raízes do estilosantes Mineirão.

(a)

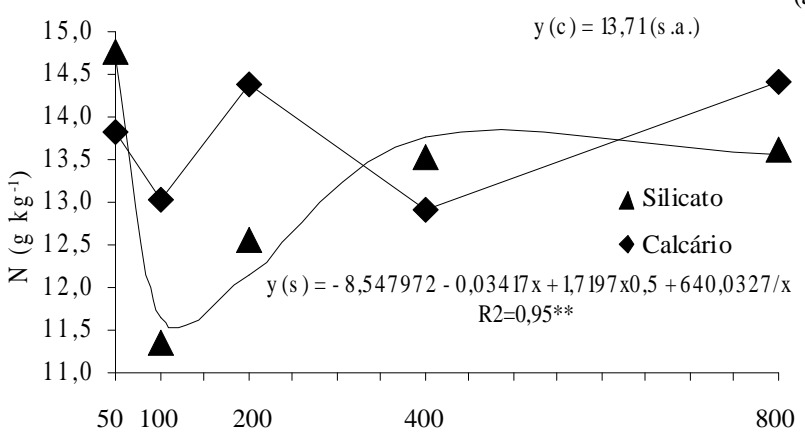

Doses de $\mathrm{P}\left(\mathrm{mg} \mathrm{dm}^{-3}\right)$

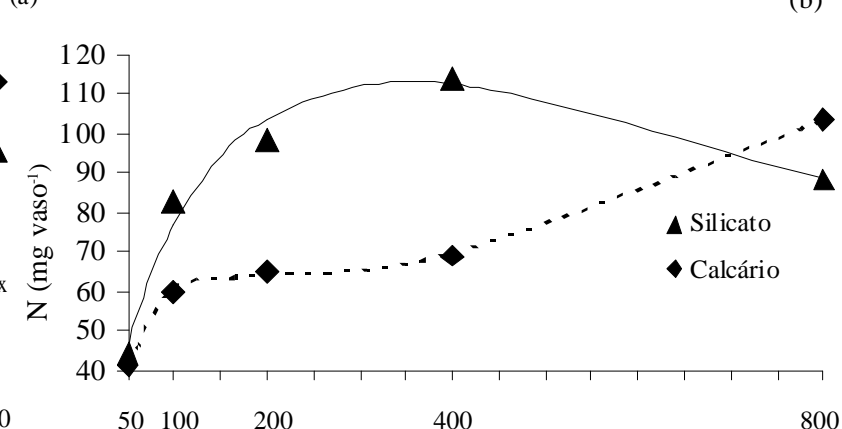

Doses de $\mathrm{P}\left(\mathrm{mg} \mathrm{dm}^{-3}\right)$

Figura 4 - Teor (a) e acúmulo (b) de N nas raízes do estilosantes Mineirão. 
ocorreu com a aplicação de $316 \mathrm{mg} \mathrm{dm}^{-3}$ de P. Ao observar conjuntamente a contagem de nódulos (Figura 2) e o acúmulo de N (Figura 4b), verificou-se que o comportamento dessas duas variáveis foi semelhante. Isso ocorreu porque a maior quantidade de nódulos presentes nas raízes, cuja correção do solo foi efetuada com silicato resultou em maior fixação biológica de $\mathrm{N}$, visto que o $\mathrm{N}$ acumulado nas raízes é resultado da soma do $\mathrm{N}$ presente na própria raiz e do $\mathrm{N}$ presente nos nódulos que se encontram aderidos a ela. Em contrapartida, a queda no $\mathrm{N}$ acumulado a partir da aplicação de $316 \mathrm{mg} \mathrm{dm}^{-3}$ de $\mathrm{P}$ na presença do silicato se deve ao menor desenvolvimento das raízes, o que resultou em uma menor superfície radicular capaz de ser infectada pelo rizóbio, reduzindo, com isso, a capacidade de fixação biológica do $\mathrm{N}$ atmosférico. Essa situação não foi observada na interação $\mathrm{P}$ x calcário, já que o máximo acúmulo de $\mathrm{N}$ (103,3 mg vaso $\left.{ }^{-1}\right)$ ocorreu com a aplicação de $800 \mathrm{mg} \mathrm{dm}^{-3}$ de $P$.

$\mathrm{Na}$ Figura 5, observa-se o efeito da interação $\mathrm{P} \mathrm{x}$ corretivos sobre o teor de $\mathrm{Ca}(\mathrm{P}<0,01)$ e sobre o $\mathrm{Ca}$ acumulado $(\mathrm{P}<0,05)$ nas raízes do estilosantes Mineirão.

Os resultados referentes aos teores de Ca nas raízes estão mais relacionados com o efeito de diluição/ concentração do que com processos metabólicos propriamente ditos. Isso ocorre porque, apesar da grande importância do Ca na nodulação, uma vez formados os nódulos, os processos de FBN e o crescimento da leguminosa ocorrem normalmente em concentrações relativamente baixas desse elemento (Faquin, 2005).

$\mathrm{O}$ acúmulo de $\mathrm{Ca}$ do Mineirão não se ajustou ao estudo de regressão para a interação $\mathrm{P}$ x silicato. Porém, nas doses 100 e $200 \mathrm{mg} \mathrm{dm}^{-3} \mathrm{de} \mathrm{P}$, esse acúmulo foi muito mais elevado na presença do silicato em relação à presença do calcário.

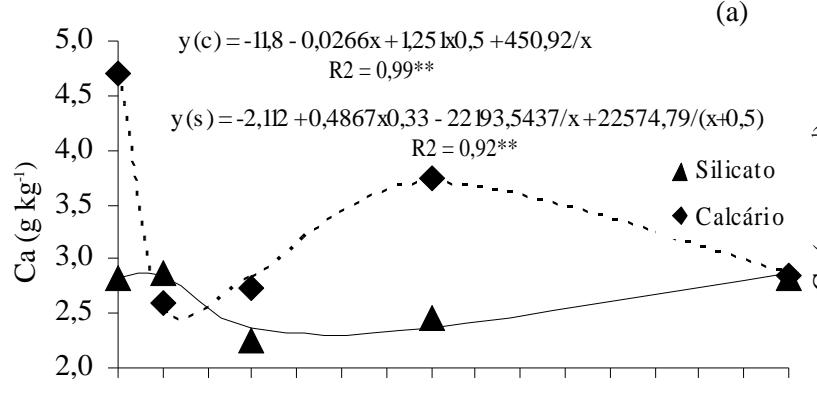

$50 \quad 100 \quad 200$

400

800

Doses de $\mathrm{P}\left(\mathrm{mg} \mathrm{dm}^{-3}\right)$
A maior demanda por Ca pelas raízes com a aplicação de 100 e $200 \mathrm{mg} \mathrm{dm}^{-3}$ de $\mathrm{P}$ na presença de silicato, seguramente é consequência do maior desenvolvimento inicial do sistema radicular. Raízes de leguminosas possuem maior CTC que as de gramíneas, apresentando, portanto, maior afinidade por cátions divalentes como é o caso do $\mathrm{Ca}^{2+}$ (Evans, 1977). Além de sua importância para o crescimento radicular, o Ca desempenha importante papel no processo de infecção das raízes pelo rizóbio (Vidor et al., 1983). Para a nodulação das leguminosas, há a necessidade maior de $\mathrm{Ca}$ do que para a planta propriamente dita (Vitti et al., 2006). Sendo assim, nos tratamentos em que a nodulação foi maior é de se esperar que a necessidade inicial de Ca também tenha sido maior.

Na Figura 6, observa-se o efeito da interação $\mathrm{P} x$ corretivos sobre o teor de $\mathrm{Mg}(\mathrm{P}<0,01)$ e das doses de $\mathrm{P}$ sobre o $\mathrm{Mg}$ acumulado $(\mathrm{P}<0,01)$ nas raízes do estilosantes Mineirão.

Os maiores teores de $\mathrm{Mg}$ foram observados para a interação P x calcário em quase todo intervalo estudado. Como a nodulação é modulada pela disponibilidade de ATP (Araújo \& Machado, 2006) e a síntese dessa molécula apresenta um requerimento essencial de $\mathrm{Mg}$ (Faquin, 2005), é de se esperar que a necessidade de $\mathrm{Mg}$ aumente com os incrementos nas doses de $\mathrm{P}$ aplicadas. Porém, mais uma vez, acentuado efeito de diluição na interação $\mathrm{P}$ x silicato, provavelmente foi a principal causa da redução nos teores de $\mathrm{Mg}$. Possivelmente, a diferença no comportamento do teor de $\mathrm{Mg}$ para a interação $\mathrm{P}$ x calcário é decorrente do menor efeito de diluição, ocorrido ao longo do intervalo estudado. Ainda é preciso salientar que, assim como ocorre para o $\mathrm{Ca}$, as necessidades de $\mathrm{Mg}$ para que a nodulação ocorra de forma satisfatória parecem não ser altas.

O máximo acúmulo de $\mathrm{Mg}\left(17 \mathrm{mg}\right.$ vaso $\left.^{-1}\right)$ ocorreu com a aplicação de $630 \mathrm{mg} \mathrm{dm}^{-3} \mathrm{de} \mathrm{P}$, independente do

Figura 5 - Teor (a) e acúmulo (b) de Ca nas raízes do estilosantes Mineirão. 
corretivo utilizado. Esse comportamento pode estar associado à baixa exigência de $\mathrm{Mg}$ pela maioria das culturas (Faquin, 2005). A complexidade existente na relação entre $\mathrm{Ca}, \mathrm{Mg}$ e nodulação também é vista como um fator importante. O Ca e o $\mathrm{Mg}$ têm efeitos marcantes e complexos no crescimento do Rhizobium e as exigências de $\mathrm{Mg}$ parecem ser maiores do que as de Ca, porém, a falta de um, até certo ponto, pode ser compensada pela abundância do segundo (Malavolta, 1976).

Na Figura 7, observa-se o efeito da interação P x corretivos sobre o $\mathrm{Zn}$ acumulado pelas raízes do estilosantes Mineirão $(\mathrm{P}<0,05)$.

Para a interação $\mathrm{P} x$ silicato, o acúmulo de $\mathrm{Zn}$ aumentou até a dose $343 \mathrm{mg} \mathrm{dm}^{-3} \mathrm{de} \mathrm{P}$, chegando ao valor máximo de $0,19 \mathrm{mg} \mathrm{vaso}^{-1}$. A partir dessa dose, o aumento no fornecimento de $\mathrm{P}$ passou a representar efeito negativo em virtude da interação PxZn. Já, quando o aumento na dose de $\mathrm{P}$ ocorreu mediante o uso de calcário como corretivo, a resposta do acúmulo de $\mathrm{Zn}$ foi linear e positiva às doses de $\mathrm{P}$, atingindo o valor máximo de $0,19 \mathrm{mg}$ vaso $^{-1}$ somente com a aplicação de $800 \mathrm{mg} \mathrm{dm}^{-3}$ de $\mathrm{P}$. O P pode aumentar a absorção de $\mathrm{Zn}$ pelas plantas, mas a interação é negativa em condições de alta concentração de $\mathrm{P}$ e baixa concentração de Zn no meio (Wallace et al., 1978).

Observam-se efeito apenas dos corretivos sobre os teores de $\mathrm{Zn}$ nas raízes do estilosantes Mineirão $(\mathrm{P}<0,01)$. Este foi maior para as plantas cultivadas no solo onde foi feita a calagem, apresentado o valor de $24,7 \mathrm{mg} \mathrm{kg}^{-1}$ contra $21,8 \mathrm{mg} \mathrm{kg}^{-1}$ no solo que recebeu o silicato. Entretanto, o simples efeito de diluição não pode ser usado exclusivamente para explicar estes resultados. A menor produção de massa seca observada a partir da aplicação

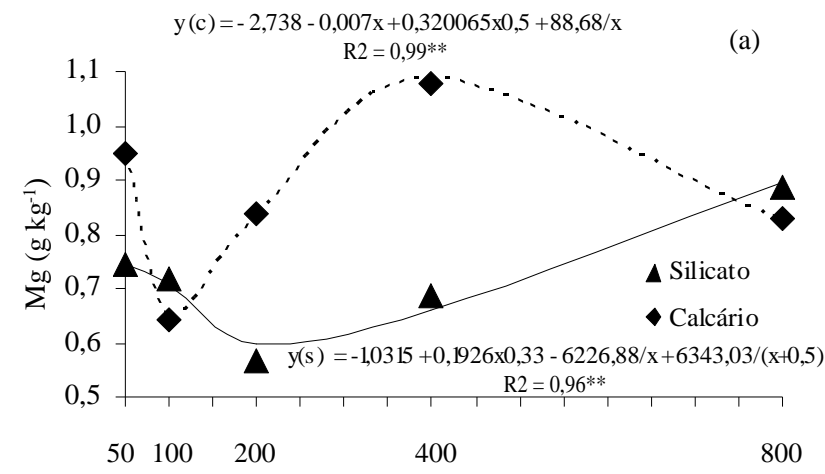

Doses de $\mathrm{P}\left(\mathrm{mg} \mathrm{dm}^{-3}\right)$

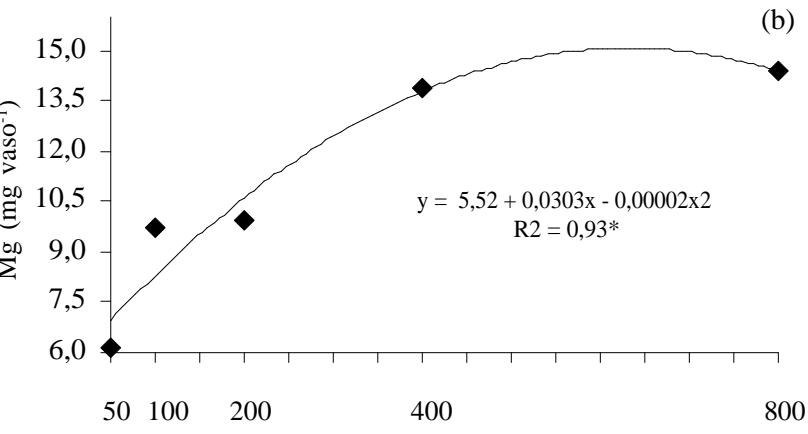

Doses de $\mathrm{P}\left(\mathrm{mg} \mathrm{dm}^{-3}\right)$

Figura 6 - Teor (a) e acúmulo (b) de Mg nas raízes do estilosantes Mineirão.

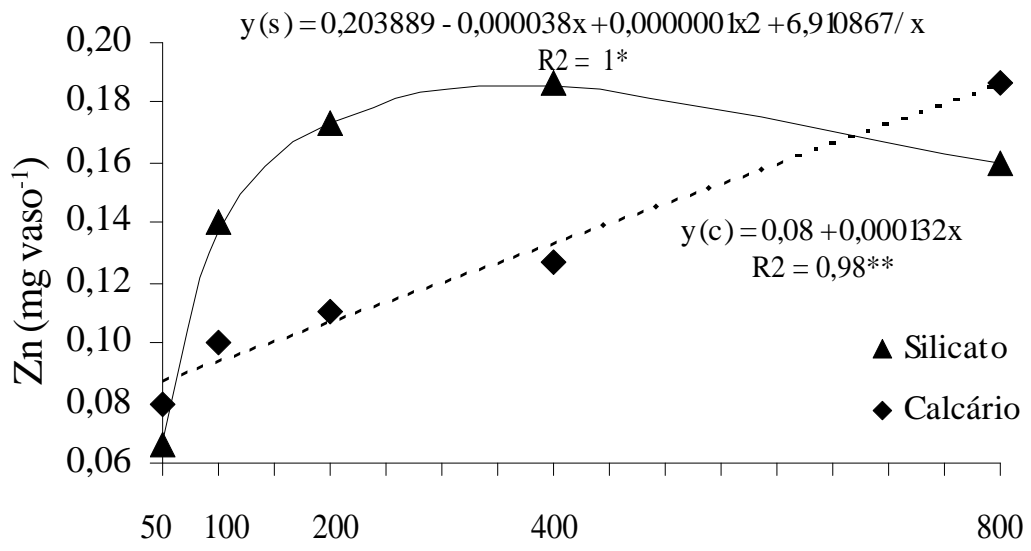

Doses de $\mathrm{P}\left(\mathrm{mg} \mathrm{dm}^{-3}\right)$

Figura 7 - Acúmulo de Zn nas raízes do estilosantes Mineirão. 
de $257 \mathrm{mg} \mathrm{dm}^{-3}$ de P na presença do silicato, aliada ao aumento linear no acúmulo de $\mathrm{P}$ e redução no acúmulo de $\mathrm{Zn}$ a partir da dose de $\mathrm{P}$ aplicada de $343 \mathrm{mg} \mathrm{dm}^{-3}$ é indicativo claro de que fatores negativos relacionados a interação $\mathrm{P}-\mathrm{Zn}$ prejudicaram o desenvolvimento do sistema radicular. A alta disponibilidade de $\mathrm{P}$ no solo pode ter inibido a absorção de $Z n$ e estimulado o crescimento da planta a ponto de diluir o teor de $\mathrm{Zn}$ nos tecidos, colocando-o em um nível abaixo do crítico. Esse fator, provavelmente, foi o principal responsável pela queda na produção de matéria seca de raízes a partir da dose $257 \mathrm{mg} \mathrm{dm}^{-3} \mathrm{de} \mathrm{P}$ na presença de silicato.

\section{CONCLUSÕES}

A produção de matéria seca de raízes, nodulação e acúmulos dos nutrientes, P, N, Ca e $\mathrm{Zn}$ do estilosantes Mineirão foram maiores quando a adubação esteve associada à silicatagem.

Na presença de silicato, a adubação fosfatada proporcionou resposta positiva em produção de matéria seca de raízes apenas até a dose $257 \mathrm{mg} \mathrm{dm}^{-3}$. Esse efeito, que não foi observado quando foi utilizado calcário, pode ser atribuído à interação negativa entre os nutrientes $\mathrm{P} e$ $\mathrm{Zn}$ em condições de alta disponibilidade de $\mathrm{P}$.

\section{REFERÊNCIAS BIBLIOGRÁFICAS}

ANDREW, C.S. Effect of calcium, $\mathrm{pH}$ and nitrogen on the growth and chemical composition of some tropical and temperate legumes: I., nodulation and growth. Australian Journal of Agricultural Research, Melbourne, v.27, p.611-623, 1976.

ANDREW, C.S.; JONES, R.K. The phosphorus nutrition of tropical forage legumes. In: ANDREW, C.S.; KAMPRATH, E.J. (Eds.). Mineral nutrition of legumes in tropical and subtropical soil. Melbourne: CSIRO, 1978. p.295-311.

ARAÚJO, A.P.; MACHADO, C.T.T. Fósforo. In: FERNANDES, M.S. (Ed.). Nutrição mineral de plantas. Viçosa, MG: UFV, 2006. p.253-280.

CARNEIRO, M.A.C.; SIQUEIRA, J.O.; CURI, N.; MOREIRA, F.M.S. Efeitos da inoculação de fungos micorrízicos arbusculares e da aplicação de fósforo no estabelecimento de forrageiras em solo degradado. Pesquisa Agropecuária Brasileira, Brasília, v.34, n.9, p.1669-1677, 1999.

CHAUDHARY, M.I.; FUJITA, K. Comparison of phosphorus deficiency effects on the growth parameters of mashbean, mungbean, and soybean. Soil Science and Plant Nutrition, Tokyo, v.44, n.1, p.19-30, 1998.

COSTA, N.L.; PAULINO, V.T.; SCHAMMAS, E.A. Produção de forragem, composição mineral e nodulação do guandu afetadas pela calagem e adubação fosfatada. Revista Brasileira de Ciência do Solo, Campinas, v.13, p.51-58, 1989.

\section{EMPRESA BRASILEIRA DE PESQUISA}

AGROPECUÁRIA. Centro Nacional de Pesquisa de

Solos. Sistema brasileiro de classificação de solos. 2.ed. Rio de Janeiro, 2006. 306p.

EVANS, P.S. Comparative root morphology of some pasture grasses and clovers. New Zealand Journal of Agriculture of Research, Melbourne, v.20, n.3, p.331335, 1977.

FAQUIN, V. Nutrição mineral de plantas. Lavras: UFLA/ FAEPE, 2005. 183p.

FERREIRA, D.F. SISVAR: um programa para análises e ensino de estatística. Revista Symposium, Lavras, v.6, p.36-41, 2008

GUSS, A.; GOMIDE, J.A.; NOVAIS, R.F. Exigências de fósforo para estabelecimento de quatro leguminosas forrageiras em solos com distintas características físicoquímicas. Revista da Sociedade Brasileira de Zootecnia, Viçosa, v.19, p.450-458, 1990.

HORST, W.J.; MARSCHNER, H. The effect of silicon on manganese tolerance of bean plants (Phaseolus vulgaris L.). Plant Soil, Dordrecht, v.50, p.287-303, 1978.

KOLLING, J.; STAMMEL, J.G.; KORNELIUS, E. Efeitos de calagem e da adubação fosfatada sobre a nodulação, nitrogênio total no tecido e produção de matéria seca de leguminosas forrageiras de clima tropical. Agronomia Sulriograndense, Porto Alegre, v.10, p.267-280, 1974.

KROLOW, R.H.; MISTURA, C.; COELHO, R.W.; SIEWERDT, L.; ZONTA, E.P. Efeito do fósforo e do potássio sobre o desenvolvimento e a nodulação de três leguminosas anuais de estação fria. Revista Brasileira de Zootecnia, Viçosa, v.33, n.6, p.2224-2230, 2004.

MALAVOLTA, E. Manual de química agrícola. São Paulo: Agronômica Ceres, 1976. 527p. 
MALAVOLTA, E.; VITTI, G.C.; OLIVEIRA, S.A. Avaliação do estado nutricional das plantas: princípios e aplicações. Piracicaba: EDUSP, 1997. 237p.

MIYAKE, Y.; TAKAHASHI, E. Effect of silicon on the growth of soybean plants in a solution culture. Soil Science Plant Nutrition, v.31, p.625-636, 1985.

MURPHY, H.E.; EDWARDS, D.G.; ASHER, C.J. Effects of aluminium on nodulation and early growth of four tropical pasture legumes. Australian Journal of Agricultural Research, Melbourne, v.35, p.663-673, 1984.

NELWAMONDO, A.; DAKORA, F.D. Silicon promotes nodule formation and nodule function in symbiotic cowpea (Vigna unguiculata). New Phytology, Palo Alto, v.142, p.463-467, 1999.

ROSOLEM, C.A.; ASSIS, J.S.; SANTIAGO, A.D. Root growth and mineral nutrition of corn hybrids as affected by phosphorus and lime. Communications in Soil Science and Plant Analysis, v.25, p.2491-2499, 1994.

SARRUGE, J.R.; HAAG, H.P. Análise química em plantas. Piracicaba: ESALQ, 1974. 56p.

SILVA, D.J. Análise de alimentos: métodos químicos e biológicos. Viçosa, MG: UFV, 1998. 165p.
SOUZA, E.A. de.; MORAES, J.C. de.; AMARAL, J.L. do.; LIBERATO, R.D.; BONELLI, E.A.; LIMA, L.R. Efeito da aplicação de silicato de cálcio em Brachiaria brizantha cv. Marandu sobre a população de ninfas do percevejo castanho das raízes Scaptocoris carvalhoi Becker, 1967, características químicas do solo, planta e produção de matéria seca. Ciência e Agrotecnologia, Lavras, v.33, n.6, p.1518-1526, Nov./dez., 2009.

SOUZA, R.F.; PINTO, J.C.; SIQUEIRA, J.O.; CURI, N.; MORAIS, A. Influência de micorriza e fósforo sobre o rendimento de matéria seca e calidade de Andropogon gayanus e Stylosanthes guianensis cultivados em um latossolo. Pasturas Tropicales, Cali, v.22, n.2, p.34-41, 2000.

VIDOR, C.; KOLLING, J.; FREIRE, J.R.J.; SCHOLLES, D.; BROSE, E.; PEDROSO, M.H.T. Fixação biológica do nitrogênio pela simbiose Rhizobium e leguminosas. Porto Alegre: IPAGRO, 1983. 52p. (Boletim técnico, 11).

VITTI, G.C.; LIMA, E.; CICARONE, F. Cálcio, magnésio e enxofre. In: FERNANDES, M.S. (Ed.). Nutrição mineral de plantas. Viçosa, MG: UFV, 2006. p.299-325.

WALLACE, A.; MUELLER, R.T.; ALEXANDER, G.V. Influence of phosphorus on zinc, iron, manganese and copper uptake by plnts. Soil Science, Baltimore, v.126, n.6, p.336-341, 1978. 